S2 Table. GO term enrichment in WGCNA modules.

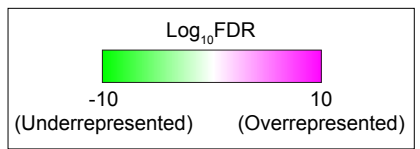

\title{
WGCNA Modules
}

\begin{tabular}{|c|c|c|c|c|c|c|c|c|c|c|c|c|c|c|c|c|c|c|c|c|c|c|c|c|c|c|}
\hline & 胥 & 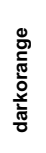 & ⿷匚 & 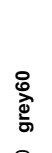 & $\begin{array}{l}\frac{0}{00} \\
\frac{\bar{z}}{2}\end{array}$ & 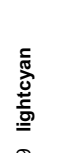 & 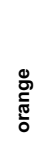 & 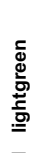 & 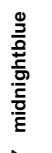 & 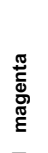 & $\begin{array}{l}\text { ष्ठ } \\
\text { ప్ర }\end{array}$ & 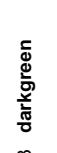 & 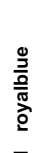 & 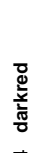 & 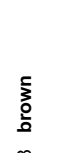 & $\frac{0}{\varrho}$ & $\frac{z}{\overline{\frac{z}{\sigma}}}$ & 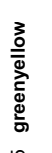 & 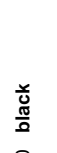 & 旁 & 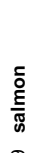 & !ِ & ळ & 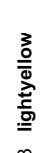 & & \\
\hline Genes in Module (\#): & $\stackrel{\text { \& }}{\circ}$ & $\bar{\infty}$ & $\widetilde{\widetilde{N}}$ & 옴 & $\stackrel{\text { : }}{\text { Dे }}$ & $\stackrel{\mathscr{R}}{=}$ & Б & $\underset{g}{\sigma}$ & 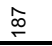 & $\overline{్ ల ~}$ & $\widehat{\mathcal{Y}}$ & 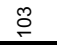 & 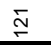 & 홍 & 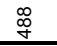 & 怘 & 寺 & $\stackrel{\text { I }}{N}$ & 足 & 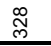 & $\stackrel{\circ}{N}$ & $\bar{\sigma}$ & $\frac{10}{4}$ & $\stackrel{\widetilde{N}}{\sim}$ & ॐ & \\
\hline Tetrapyrole biosynthesis & 6.7 & 0.0 & 0.0 & 0.0 & 0.0 & 0.0 & 0.0 & 0.0 & 0.0 & 0.0 & 0.0 & 0.0 & 0.0 & 0.0 & 0.0 & 0.0 & 0.0 & 0.0 & 0.0 & 0.0 & 0.0 & 0.0 & 0.0 & 0.0 & 0.0 & \\
\hline Uroporphirinogen decarboxylase & 2.7 & 0.0 & 0.0 & 0.0 & 0.0 & 0.0 & 0.0 & 0.0 & 0.0 & 0.0 & 0.0 & 0.0 & 0.0 & 0.0 & 0.0 & 0.0 & 0.0 & 0.0 & 0.0 & 0.0 & 0.0 & 0.0 & 0.0 & 0.0 & & \\
\hline Isoprenoid biosynthesis & 1.7 & 0.0 & 0.0 & 0.0 & 0.0 & 0.0 & .0 & 0.0 & 0.0 & .0 & 0.0 & 0.0 & 0.0 & 0.0 & 0.0 & 0.0 & 0.0 & .0 & 0.0 & 0.0 & 0.0 & 0.0 & 0.0 & .0 & & \\
\hline Membrane part & 0.0 & 5.2 & 0.0 & 0.0 & 0.0 & 0.0 & 0.0 & 0.0 & 0.0 & 0.0 & 0.0 & 0.0 & 0.0 & 0.0 & 0.0 & 0.0 & 0.0 & 0.0 & 0.0 & 0.0 & 0.0 & 0.0 & 0.0 & 0.0 & 0.0 & \\
\hline Photosystem II & 0.0 & 3.2 & 0.0 & 0.0 & 0.0 & 0.0 & 0 & 0.0 & 0.0 & 0.0 & 0.0 & 0.0 & 0.0 & 0.0 & 0.0 & 0.0 & 0.0 & 0.0 & 0.0 & 0.0 & 0.0 & 0.0 & 0.0 & 0.0 & 0 & \\
\hline Nucleosome core & 0.0 & 0.0 & 4.6 & 0.0 & 0.0 & 0.0 & 0.0 & 0.0 & 0.0 & 0.0 & 0.0 & 0.0 & 0.0 & 0.0 & 0.0 & 0.0 & 0.0 & 0.0 & 0.0 & 0.0 & 0.0 & 0.0 & 0.0 & 0.0 & 0.0 & \\
\hline Histone-fold & 0.0 & 0.0 & 4.2 & 0.0 & 0.0 & 0.0 & 0.0 & 0.0 & 0.0 & 0.0 & 0.0 & 0.0 & 0.0 & 0.0 & 0.0 & 0.0 & 0.0 & 0.0 & 0.0 & 0.0 & 0.0 & 0.0 & 0.0 & 0.0 & & \\
\hline Nucleosome assembly & 0.0 & 0.0 & 3.1 & 0.0 & 0.0 & 0.0 & 0.0 & 0.0 & 0.0 & 0.0 & 0.0 & 0.0 & 0.0 & 0.0 & 0.0 & 0.0 & 0.0 & 0.0 & 0.0 & 0.0 & 0.0 & 0.0 & 0.0 & 0.0 & 0.0 & \\
\hline Histone 2A & 0.0 & 0.0 & 2.7 & 0.0 & 0.0 & 0.0 & 0.0 & 0.0 & 0.0 & 0.0 & 0.0 & 0.0 & 0.0 & 0.0 & 0.0 & 0.0 & 0.0 & 0.0 & 0.0 & 0.0 & 0.0 & 0.0 & 0.0 & 0.0 & & \\
\hline Establishment of protein localization & 0.0 & 0.0 & 1.0 & 0.0 & 0.0 & 0.0 & 0.0 & 0.0 & 0.0 & 0.0 & 0.0 & 0.0 & 0.0 & 0.0 & 0.0 & 0.0 & 0.0 & 0.0 & 0.0 & 0.0 & 0.0 & 2.0 & 0.0 & 0.0 & 0.0 & \\
\hline Mismatch repair & 0.0 & 0.0 & 0.0 & 0.0 & 3.2 & 0.0 & 0.0 & 0.0 & 0.0 & 0.0 & 0.0 & 0.0 & 0.0 & 0.0 & 0.0 & 0.0 & 0.0 & 0.0 & 0.0 & 0.0 & 0.0 & 0.0 & 0.0 & 0 & & \\
\hline DNA $\mathrm{r}$ & 0.0 & 0.0 & 0.0 & 0.0 & 3.1 & 0.0 & 0.0 & 0.0 & 0.0 & 0.0 & 0.0 & 0.0 & 0.0 & 0.0 & 0.0 & 0.0 & 0.0 & 0.0 & 0.0 & 0.0 & 0.0 & 0.0 & 0.0 & .0 & 0.0 & \\
\hline Proteasome complex & 0.0 & 0.0 & 0.0 & 0.0 & 0.0 & 2.0 & 0.0 & 0.0 & 0.0 & 0.0 & 0.0 & 0.0 & 0.0 & 0.0 & 0.0 & 0.0 & 0.0 & 0.0 & 0.0 & 0.0 & 0.0 & 0.0 & 0.0 & 0.0 & 0.0 & \\
\hline Catabolic pro & 0.0 & 0.0 & 0.0 & 0.0 & 0.0 & 1.4 & 0.0 & 0.0 & 0.0 & 0.0 & 0.0 & 0.0 & 0.0 & 0.0 & 0.0 & 0.0 & 0.0 & 0.0 & 0.0 & 0.0 & 0.0 & 0.0 & 0.0 & 0.0 & 0.0 & \\
\hline Protein $\mathrm{pl}$ & 0.0 & 0.0 & 0.0 & 0.0 & 0.0 & 0.0 & 0.0 & 0.0 & 0.0 & 0.0 & 0.0 & 4.0 & 0.0 & 0.0 & 0.0 & 0.0 & 0.0 & 0.0 & 0.0 & 0.0 & 0.0 & 0.0 & 0.0 & .0 & 0.0 & \\
\hline Mot & 0.0 & 0.0 & 0.0 & 0.0 & 0.0 & 0.0 & 0.0 & 0.0 & 0.0 & 0.0 & 0.0 & 1.3 & 0.0 & 0.0 & 0.0 & 0.0 & P0 0 & 0.0 & 0.0 & 0.0 & 0.0 & 0.0 & 1.0 & .0 & & \\
\hline Negative regula & 0.0 & 0.0 & 0.0 & 0.0 & 0.0 & 0.0 & 0.0 & 0.0 & 0.0 & 0.0 & 0.0 & 0.0 & 3.4 & 0.0 & 0.0 & 0.0 & 0.0 & 0.0 & 0.0 & 0.0 & 0.0 & 0.0 & 0.0 & 0.0 & .0 & \\
\hline Seri & 0. & 0.0 & 0.0 & 0.0 & 0.0 & 0.0 & 0.0 & 0.0 & 0.0 & 0.0 & 0.0 & 0.0 & 3.1 & 0.0 & 0.0 & 0.0 & 0.0 & 0.0 & 0.0 & 0.0 & 0.0 & 0.0 & 0.0 & .0 & & \\
\hline Prote & 0.0 & 0.0 & 0.0 & 0.0 & 0.0 & 0.0 & 0.0 & 0.0 & 0.0 & 0.0 & 0.0 & 0.0 & 1.4 & 0.0 & 0.0 & 0.0 & 0.0 & 0.0 & 0.0 & 0.0 & .0 & 0.0 & 0.0 & .0 & 0.0 & \\
\hline in modification & 0.0 & 0.0 & 0.0 & 0.0 & 0.0 & 0.0 & 0.0 & 0.0 & 0.0 & 0.0 & 0.0 & 0.0 & 0.0 & 0.0 & 0.0 & 0.0 & 0.0 & 0.0 & 2.2 & 0.0 & 0.0 & 0.0 & 0.0 & .0 & .0 & \\
\hline Zn-finger & 0.0 & 0.0 & 0.0 & 0.0 & 0.0 & 0.0 & 0.0 & 0.0 & 0.0 & 0.0 & 0.0 & 0.0 & 0.0 & 0.0 & 0.0 & 0.0 & 0.0 & 0.0 & 1.3 & 0.0 & 0.0 & 0.0 & 1.0 & .0 & 0.0 & \\
\hline NA topo-isomerase II & 0.0 & 0.0 & 0.0 & 0.0 & 0.0 & 0.0 & 0.0 & 0.0 & 0.0 & 0.0 & 0.0 & 0.0 & 0.0 & 0.0 & 0.0 & 0.0 & 0.0 & 0.0 & 1.1 & 0.0 & 0.0 & 0.0 & 0.0 & 0.0 & POP & \\
\hline ribosome & 0.0 & 0.0 & 0.0 & 0.0 & 0.0 & 0.0 & 0.0 & 0.0 & 0.0 & 0.0 & 0.0 & 0.0 & 0.0 & 0.0 & 0.0 & 0.0 & 0.0 & 0.0 & 0.0 & 21.3 & .0 & 0.0 & 0 & 0.0 & & \\
\hline Photos & 0.0 & 0.0 & 0.0 & 0.0 & 0.0 & 0.0 & 0.0 & 0.0 & 0.0 & 0.0 & 0.0 & 0.0 & 0.0 & 0.0 & 0.0 & 0.0 & 0.0 & 0.0 & 0.0 & 3.6 & .0 & 0.0 & 10 & 0.0 & $0 . c$ & \\
\hline RNA & 0.0 & 0.0 & 0.0 & 0.0 & 0.0 & 0.0 & 0.0 & 0.0 & 0.0 & 0.0 & 0.0 & 0.0 & 0.0 & 0.0 & 0.0 & 0.0 & 0 & 0.0 & 0.0 & 3.3 & 0 & 0 & 0 & 0.0 & 0. & \\
\hline Ribon & 0.0 & 0.0 & 0.0 & 0.0 & 0.0 & 0.0 & 0.0 & 0.0 & 0.0 & 0.0 & 0.0 & 0.0 & 0.0 & 0.0 & 0 & 0.0 & 0.0 & .0 & 0.0 & 2.1 & 0 & 0.0 & 0 & .0 & 0.0 & \\
\hline Nucl & 0.0 & 0.0 & 0.0 & 0.0 & 0.0 & 0.0 & 0.0 & 0.0 & 0.0 & 0.0 & 0.0 & 0.0 & 0.0 & 0.0 & 0.0 & 0.0 & 0.0 & 0.0 & 0.0 & 1.6 & 0.0 & 0.0 & 0 & 0.0 & 0 & \\
\hline ivity & 0.0 & 0.0 & 0.0 & 0.0 & 0.0 & 0.0 & 0.0 & 0.0 & 0.0 & 0.0 & 0.0 & 0.0 & 0.0 & 0.0 & 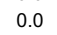 & .0 & 0.0 & .0 & 0.0 & 0. & .7 & 0.0 & 0.0 & .0 & 0.0 & \\
\hline Dam & & 0.0 & 00 & 0.0 & 0.0 & 00 & 0.0 & 0.0 & 00 & 0.0 & 0.0 & 0.0 & 0.0 & 0.0 & 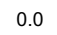 & .0 & & 0 & 0.0 & & 2 & 0.0 & & .0 & & \\
\hline RI & 0.0 & 0.0 & 0.0 & 0.0 & 0.0 & 0.0 & 0.0 & 0.0 & 0.0 & 0.0 & 0.0 & 0.0 & 0.0 & 0.0 & 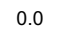 & 0.0 & 0.0 & 0. & 0.0 & 0.0 & 0.0 & 14 & 0 & .0 & 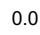 & \\
\hline Rib & 0.0 & 0.0 & 0.0 & 0.0 & 0.0 & 0.0 & 0.0 & 0.0 & 0 & 0.0 & 0.0 & 0.0 & 0.0 & 0.0 & 0.0 & 0.0 & 0.0 & 0.0 & 0.0 & 0.0 & .0 & 9.6 & 0 & .0 & & \\
\hline & 0.0 & 0.0 & 0.0 & 0.0 & $c_{0}$ & 0.0 & 0.0 & 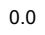 & 0.0 & 0.0 & 0.0 & 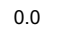 & 0 & 1.0 & 0.0 & 0.0 & 0.0 & 0.0 & .0 & 0.0 & 0.0 & 7.0 & 0.0 & 0.0 & 0.6 & \\
\hline tRNA & 0.0 & 0.0 & 0 & 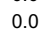 & ( & 0. & 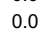 & 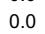 & 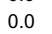 & S & o & 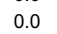 & 0.0 & 0 & & 0 & & 0.0 & 0 & & 0 & & & 0.0 & & \\
\hline & & 0.0 & 0.0 & 0 & 0.0 & 0.0 & 0.0 & 0.0 & 0 & 0.0 & 0.0 & 0.0 & 0.0 & 0.0 & 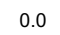 & 0.0 & 0.0 & c & 0.0 & 0.0 & 0. & 6 & 0 & 0.0 & 0.0 & \\
\hline & 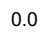 & 0.0 & 0. & 0.0 & 0.0 & 0.0 & 0.0 & 0.0 & 0 & 0.0 & 0.0 & 0.0 & 0.0 & 0.0 & 0.0 & .0 & & 0.0 & 0.0 & 0.0 & 0.0 & 6 & 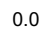 & 0.0 & & \\
\hline & 0 & 0.0 & 0.0 & 0.0 & 0.0 & 0.0 & 0.0 & 0.0 & 0.0 & 0.0 & 0.0 & 0.0 & 0.0 & 0.0 & 0.0 & 0.0 & 0.0 & 0.0 & 0.0 & 0. & 0. & 2 & 0 & 0.0 & 0.0 & \\
\hline & 0.0 & 0.0 & 0.0 & 0.0 & 0.0 & 0.0 & 0.0 & 0. & 0.0 & 0.0 & 0.0 & 0.0 & 0.0 & 0.0 & 0.0 & 0.0 & 0 & 0.0 & 0.0 & 0.0 & 0.0 & 1.4 & 0 & 0.0 & & \\
\hline & & 0.0 & 0. & D & 0.0 & 0.0 & 0.0 & م0 & 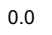 & 0.0 & 0 & 0.0 & 0.0 & 0 & 0 & 0.0 & & 0.0 & 0. & 0. & 0.0 & & -1.5 & 0.0 & & \\
\hline & 0. & 0.0 & 0.0 & 0 & 0.0 & 0.0 & 0.0 & .0 & 0.0 & 0.0 & .0 & 0.0 & 0.0 & 0.0 & 0.0 & .0 & 0.0 & 0.0 & 0.0 & 0.0 & 0.0 & 0.0 & 4.3 & .0 & 0.0 & \\
\hline & 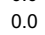 & 0.0 & 0. & 0 & 0.0 & 0.0 & 0.0 & 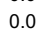 & 0 & 0.0 & 0 & 0.0 & 0.0 & 0 & 0. & 0.0 & & 0. & 0.0 & & 0.0 & & & 0.0 & & \\
\hline & 0 & 0.0 & 0.0 & 0 & 0.0 & 0.0 & 0.0 & 0.0 & ) & 0.0 & .0 & 0.0 & 0.0 & 0.0 & 0. & 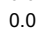 & 0.0 & 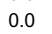 & 10 & 0.0 & 0 & 0.0 & 3 & 1.0 & 0.0 & \\
\hline & & 0.0 & 0.0 & & 0 & 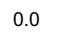 & & 0 & & & & & & & & & & $0.0+2-3$ & 0.0 & & & & & 1. & & \\
\hline biosynthetic & 0 & 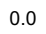 & 0.0 & 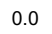 & 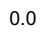 & 0.0 & 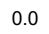 & 0.0 & 0.0 & 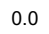 & 0 & 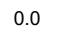 & 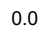 & 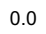 & 0. & 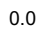 & 0.0 & 0.0 & 00 & 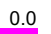 & 0.0 & .0 & 0 & & & \\
\hline & 0. & 0.0 & 0.0 & 0.0 & 0.0 & 0.0 & & 0.0 & & & 0.0 & & & & & & & & & & & & & & & \\
\hline & 0.0 & 0.0 & 0.0 & 0.0 & 0.0 & 0.0 & 0.0 & 0. & 0. & 0.0 & 0 & 0.0 & 0.0 & 0.0 & -2.5 & 0.0 & 0.0 & 0.0 & & 0. & & & 0.0 & 0 & 0.0 & \\
\hline Gene expression & 0.0 & 0.0 & 0.0 & 0.0 & 0.0 & 0.0 & 0.0 & 0.0 & 0.0 & 0.0 & 0.0 & 0.0 & 0.0 & 0.0 & -5.6 & 0.0 & 0.0 & 0.0 & & & & 14.3 & 0.0 & 0.0 & 4.3 & \\
\hline
\end{tabular}

